\title{
Shock Propagation Through Cross-Learning in Opaque Networks*
}

\author{
Jan Schneemeier $^{\dagger}$ \\ Indiana University - Kelley School of Business
}

December 4, 2018

\begin{abstract}
This paper studies information transmission in opaque networks with uncertain inter-firm linkages. Local traders can identify their firm's direct neighbors but are unsure about these firms' linkages to other firms. This uncertainty renders prices of neighboring firms difficult to interpret and leads to the propagation of shocks across firms. Payoff-relevant information diffuses slowly and there is excess comovement between fundamentally unrelated assets. Traders and firms in higher network layers suffer from less informative prices and invest less efficiently. Surprisingly, more volatile noise trading can render stock prices more efficient in opaque networks as it discourages cross-learning and reduces the propagation of unrelated shocks.
\end{abstract}

Keywords: cross-learning, information transmission, financial efficiency, network uncertainty.

JEL Classification: D83, D85, G14.

${ }^{*}$ This paper benefitted from conversations with Jean-Edouard Colliard, Alex Edmans, Thierry Foucault, Tarek Hassan, Craig Holden, Juhani Linnainmaa, Jordan Martel, Thomas Mertens, Alberto Teguia, Johannes Tischer, Semih Uslu, Jessie Wang, Steven Xiao, and Liyan Yang. I also thank seminar and conference participants at the Federal Reserve Board of Governors, Frankfurt School of Finance \& Management, Indiana University (Kelley), University of Virginia (McIntire \& Darden), CFR Cologne, FIRS, MFA, Midwest Macro Meetings, NFA, Paris December Finance Meetings, and SGF. This paper was previously titled "Shock Propagation Through Cross-Learning with Costly Price Acquisition."

${ }^{\dagger}$ Email: jschnee@iu.edu; Website: www.jan-schneemeier.com 


\section{Introduction}

A focal role of stock prices is to aggregate the private information of sophisticated traders (Grossman and Stiglitz, 1980). Other market participants can then rely on these costless endogenous signals to invest more efficiently. In particular, traders in related assets (e.g. the stock of a peer firm) can benefit from these price signals if they reveal information about a common shock. What makes price signals especially attractive for these non-local traders is that they reveal information without exposing the traders to adverse selection from trading directly against the informed local traders. In actual markets, however, a natural drawback to this rationale is the enormous complexity of inter-firm linkages. ${ }^{1}$ Therefore, it requires a substantial amount of sophistication to detect the set of firms that actually provides payoff-relevant information for a given asset and to assess the exact magnitude of this information overlap. What is more, the linkages of these connected firms to other firms have to be taken into account as well to learn efficiently from these prices.

In this paper, I analyze this problem in a rational expectation equilibrium setting with multiple assets (firms) that are pairwise connected in a linear network. Therefore, each asset's payoff is correlated with that of its direct upstream and downstream neighbor but uncorrelated with all other payoffs. Informed traders specialize in one asset, i.e. they collect precise information about local fundamentals and linkages but are relatively uninformed about all non-local shocks. To invest more efficiently, local specialists improve the assessment of their asset's composite payoff by learning additional information from the price of connected assets. Importantly, the underlying network is opaque such that local

${ }^{1}$ There is a considerable accounting literature on optimal risk-factor disclosures, e.g. in a firm's 10-K. In particular, Hope et al. (2016) find a significant, positive market reaction to the Specificity of the risk-factor disclosures indicating a significant amount of market uncertainty. Ellis et al. (2012) provide evidence that firms try to conceal the identities of their major customers despite reporting requirements by the SEC. 
specialists face uncertainty about the magnitude of inter-firm linkages of distant firms. This uncertainty renders it more difficult to assess the extent to which prices of connected assets reflect local information.

In the main model, I deliberately disregard all sources of exogenous noise in prices and assume that each asset is only traded by perfectly informed local specialists. These specialists observe the local component of their asset's payoff and know the exact magnitude of its exposure to the next, more downstream asset in the network. As a benchmark, I first shut down possible variation in these cross-asset linkages and analyze a fully transparent network. Consequently, local traders' knowledge about their asset's linkage to the next firm immediately allows them to infer the connections between all other assets. In this fully transparent network, local traders can easily invert the price system to uncover the perfect information of informed traders in the downstream market. The price in the downstream asset also reflects information about this firm's downstream neighbor as specialists in all markets learn from other prices. However, these non-local traders' cross-learning from another asset can be easily undone by another specialist such that each stock price can be transformed into an unbiased signal about local information. Equilibrium stock prices in this benchmark equilibrium are thus fully revealing and equal to the actual realized asset payoffs.

Next, I switch on opacity and assume that the individual linkages between firms are randomly drawn from a normal distribution. Local specialists only know the realized value of their asset's exposure but face uncertainty about that for all other firms. In particular, the variance of the distribution for inter-firm linkages measures the degree of opacity in the network. A higher average deviation from the mean linkage between two neighboring firms increases non-local traders uncertainty about the connectivity between 
other firms. This uncertainty is particularly important for a local specialist (e.g. in asset $i$ ) who wants to learn additional information from the connected asset $i-1$. The specialist knows that the price of this connected asset is driven by local information but also by cross-learning from local specialists in asset $i-1$ from their neighbor, firm $i-2$. Network opacity obfuscates the information mix in the price of firm $i-1$ and makes it impossible to perfectly filter out local information.

In the model, financial markets are populated by informed specialized traders who trade claims to the local firm's terminal payoff. This payoff depends on two components, (i) a local fundamental shock and (ii) the local fundamental shock of the firm's downstream neighbor times the strength of the two firms' linkage. This overlapping shock structure leads to a linear network. Local traders know the local component of the payoff and the asset's exposure to the non-local component perfectly. They are, however, unsure about the non-local component in the asset's payoff and seek to improve their assessment of this shock based on the available stock prices in the economy.

In equilibrium, each firm's stock price reflects the local traders' perfect signal about the local fundamental together with their imperfect expectation of the non-local payoff component. This latter component depends on the stock prices of other (more downstream) firms in the network. For instance, traders in asset 2, which is connected to the most downstream asset 1, rely on this firm's price to learn additional information about the shared payoff component. Because asset 1 is not connected to another firm and there is no additional noise in prices, the price of asset 1 perfectly reveals this component to traders in asset 2. For traders in more upstream markets like e.g. 3, however, the learning problem is much more complex. These traders would like to learn information about the shared shock with their downstream neighbor from its price. The price of asset 2, however, also 
reflects the local traders' cross-learning from price 1. Given that the exposure between firms 1 and 2 is unknown to traders in market 3, they are unsure how much variation in the price of 2 is driven by local fundamentals. As a result, they face a comparative disadvantage compared to more downstream traders and cannot retrieve the shared payoff component from prices.

The inability of upstream firms to filter out non-local noise from their downstream neighbors' prices leads to the propagation of shocks. In particular, shocks from all downstream firms end up affecting the stock prices of upstream firms. Therefore, precisely the fact that upstream firms cannot perfectly use all information in their downstream neighbor's prices leads to contagion despite the absence of exogenous noise. Interestingly, the impact of opacity on shock propagation is twofold. First, opacity slows down the diffusion of payoff-relevant information from the connected asset because it renders this signal more difficult to interpret. Second, opacity also connects prices of firms that are fundamentally unrelated. As a result, firms like 1 and 3 that are only indirectly connected through their common neighbor 2, are correlated ex post, based on returns or prices.

A key insight of the model is that the impact of network opacity depends critically on the position of firms (or assets) in the network. Assets in the two lowest layers are, by definition, not exposed to uncertainty regarding their downstream neighbor's exposure to other firms. For firms in higher layers, however, this source of uncertainty exposes these firms to non-local shocks from all downstream firms. In an extension of the main model, I allow for a feedback effect (Bond et al., 2012) between stock prices and firm investment. As a result, firm managers base their investment decision, in part, on the stock price of their downstream neighbor to improve investment efficiency. Recent empirical evidence in Foucault and Fresard (2014), Dessaint et al. (2018), and Williams and Xiao 
(2017) suggests that firm investment indeed responds to information (and noise) in prices of related firms. In opaque networks, upstream firms face a comparative disadvantage vis-a-vis downstream firms because they can extract less valuable information from the price system. Consequently, these firms are less valuable and carry a higher risk premium which fits the empirical findings in Gofman et al. (2018).

In another extension of the main model, I introduce firm-specific noisy supply to study the interaction between opacity risk and other sources of exogenous variation in prices. I show that, as expected, higher noisy supply risk leads to less informative prices for downstream firms that do not face opacity risk. For upstream firms, however, the effect of noisy supply on price efficiency is ambiguous. On the one hand, there is a negative direct effect because more noisy supply adds more non-fundamental variation to price signals of connected firms. On the other hand, however, there is also a positive indirect effect because more noisy supply reduces the weight traders in connected markets place on price signals from distant markets which reduces the propagation effect. If the degree of opacity is large enough, the indirect effect dominates and price efficiency increases in response to higher supply risk.

This paper mainly contributes to two literatures. The literature on shock propagation or contagion in financial markets and that on information transmission in the presence of structural uncertainty or ambiguity. Starting with the former, the existing literature has highlighted several channels that can lead to information-based contagion in financial markets. First, multi-asset trading models like Admati (1985) and King and Wadhwani (1990) highlight a correlated-information channel such that prices of related assets serve as informative signals and transmit local information together with local noise. ${ }^{2}$ Sec-

${ }^{2}$ More recently Veldkamp (2006) and Mondria (2010) have shown that traders' rational attention allocation can lead to comovement between unrelated assets as well. 
ond, Kodres and Pritsker (2002) show that portfolio rebalancing can mislead uninformed traders and lead to shock propagation, while Pasquariello (2007) emphasizes the role of information heterogeneity and imperfect competition among insiders. In Cespa and Foucault (2014) liquidity providers learn information from related market prices which can lead to a self-enforcing positive relationship between price informativeness and liquidity, while Foucault and Fresard (2014) study a two-firm feedback model with information transmission through stock prices. Goldstein et al. (2014) analyze a two-asset model in the spirit of Grossman and Stiglitz (1980) with two classes of traders with different trading opportunities that features multiple equilibria and possible price jumps. My paper complements these papers and offers a new explanation for shock propagation that relies on the traders' imperfect information about the network structure, more precisely non-local inter-firm linkages. As a result, this novel framework allows me to tie the propagation of shocks to the opacity of the network and the position of different firms in the network which is not discussed in any of the aforementioned papers.

Second, my paper is also related to the literature on uncertainty or ambiguity about other market participants or firms. Easley et al. (2014) study a setting with ambiguityaverse investors that are uncertain about the effective risk tolerance of other traders and study implications for expected returns and welfare. Banerjee and Green (2015) analyze a dynamic learning model in which some traders are uncertain whether others are trading on information or noise. In Mele and Sangiorgi (2015) traders face Knightian uncertainty about fundamentals and are able to acquire additional information. In their model information acquisition can become a strategic complement which can lead to multiple equilibria. ${ }^{3}$ Finally, Armstrong et al. (2013) and Heinle et al. (2018) consider models with

${ }^{3}$ Relatedly, Vives and Yang (2016) analyze a single-firm setting with costly interpretation of prices which generates an endogenous source of noise trading. In their setting, strategic complementarities in sophistication acquisition can also lead to multiple equilibria. 
uncertain exposure to risk factors in single-firm settings. The main difference with respect to this literature is twofold. First, I consider a different dimension of uncertainty by focussing on uncertainty about linkages between non-local firms. To model this friction, it is absolutely necessary to step away from a single-firm setup and analyze a multi-asset network. Second, I study different implications. The main focus of the paper is on the types of shocks that end up affecting the different stock prices, their magnitude and their impact on the informational content of prices for firms in different layers of the network.

The remainder of this paper is organized as follows. Section 2 sets up the model. Section 3 solves for the financial market equilibrium in a benchmark economy without opacity and the general model. Section 4 discusses the implications for shock propagation and price efficiency. Section 5 analyzes two model extensions and empirical predictions and Section 6 concludes.

\section{The Model}

The economy consists of multiple firms indexed by $i \in\{1, \ldots, N\}$ with $N \geq 3$ that are connected to each other in a network. To simplify, I assume the firms to be located in a linear network with $N$ layers such that each firm's index corresponds to its vertical position. One natural interpretation of this setup is a vertical supply chain but one can also think of the different firms as being peers in overlapping product markets.

Each firm generates a random payoff $\theta_{i}$ which is correlated with the payoff of both direct neighbors $i-1$ and $i+1$. Claims to this terminal payoff are traded in secondary financial markets. Two time periods exist. In $t=1$, the financial market is active and stock prices are determined. In $t=2$, payoffs are realized and traders get paid. 


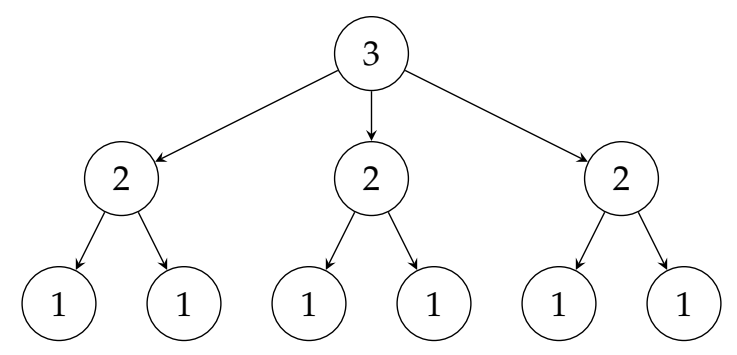

Figure 1: Example of a linear network with three layers.

\section{Payoffs and Information Sets}

The $N$ firms are located in a linear network as depicted in Figure 1. In case of a supply chain, production of final goods would start in layer "3" and move towards the most downstream firms ("1") selling it to customers. For simplicity, I assume that each layer consists of a single, representative firm.

Along the linear network, neighboring firms are exposed to a common shock such that their payoffs $\left(\theta_{i}\right)$ or fundamentals are correlated. For example, in Figure 1 the payoff of firm $i=3$ is correlated with that of its downstream neighbor $(i=2)$ but uncorrelated with that of the most downstream firm ( $i=1)$. More precisely, I assume that $\theta_{i}$, the payoff of firm $i$, equals the sum of two components: ${ }^{4}$

$$
\theta_{i} \equiv e_{i}+\rho_{i} e_{i-1} \quad \forall i \in\{1, \ldots, N\}
$$

The two components are independent, i.e. $e_{i} \stackrel{i i d}{\sim} \mathcal{N}\left(0, \sigma_{e}^{2}\right)$ for all firms. Intuitively, each firm's payoff is mainly determined by the local shock $e_{i}$, which also affects the payoff of the firm's upstream neighbor. Vice versa, $\theta_{i}$ also depends on the local shock of the firm's downstream neighbor, $e_{i-1}$. The random variable $\rho_{i} \stackrel{i i d}{\sim} \mathcal{N}\left(\bar{\rho}, \sigma_{\rho}^{2}\right)$ determines the strength and sign of this effect, and thus the degree of fundamental entanglement in the economy. Therefore, the underlying network structure allows for positive and ${ }^{4}$ Several papers in the finance literature assume that the fundamental value is affected by more than one shock. See Goldstein and Yang (2015) or Kondor (2012) for recent examples. 
negative relationships between neighboring firms. ${ }^{5}$ By definition, the most downstream firm $(i=1)$ is not connected to another firm, i.e. $\rho_{1}=0$ with certainty. Consequently, this structure for $\theta_{i}$ implies that all intermediate firms share a common shock with their up- and downstream neighbor. This cross-exposure in productivity shocks is important to give traders of these firms' stock an incentive to cross-learn, i.e. to learn from prices of other firms in the network.

A crucial feature of the model is that local agents (traders and managers, introduced later), are well-informed about local shocks $\left(e_{i}\right.$ and $\rho_{i}$ ) but face asymmetric information about non-local shocks $\left(e_{-i}\right.$ and $\left.\rho_{-i}\right)$. For simplicity, I assume that local agents observe all local shocks perfectly and only know the prior distributions for non-local shocks.

Therefore this information structure captures two dimensions of uncertainty, fundamental uncertainty and network uncertainty. The former is related to $e_{-i}$, the latter to $\rho_{-i}$. Fundamental uncertainty reflects the fact that specialized traders are most likely precisely informed about local or internal factors that determine the local firm's future productivity and therefore payoff $\left(e_{i}\right)$ but are more uncertain about non-local or external factors that are also relevant for the firm's productivity. Examples of such non-local factors, especially in a production network, include the downstream firm's future demand or economic health. Network uncertainty describes a different source of risk. It reflects the notion that local agents are more precisely informed about the local firm's exposure than other agents. For example, traders in the market of the intermediate firms on a supply chain (e.g. $i=2$ ) are expected to know, to a large extent, this firm's exposure to the downstream firm $i=1$. For firm $i=2$ 's upstream neighbor, however, these connections are less transparent and, most of the time, only revealed after the fact. As I formally show below, this additional source

${ }^{5}$ In case of a production network, it is most natural to consider $\bar{\rho} \in[0,1]$ with a relatively "small" variance such that the most likely values for $\rho_{i}$ lie between zero and one. If two firms are competitors, negative values for $\rho_{i}$ are more intuitive. 
of risk makes it harder for traders of firm $i$ to correctly interpret the price signal based on $p_{i-1}$ and thus poses an additional source of risk for these agents.

\section{Trading in Financial Markets}

Traders are risk-neutral and specialized in trading one of the $N$ firms. ${ }^{6}$ Therefore, claims to each firm's terminal payoff are traded by a unit continuum of local speculators indexed by $(i, j)$. For simplicity, I assume that traders in asset $i$ are identical, i.e. they observe the local shocks $\left(e_{i}\right.$ and $\left.\rho_{i}\right)$ perfectly but are uninformed about all other shocks. ${ }^{7}$ Moreover, speculators can condition their trades on all stock prices as in Goldstein et al. (2014). ${ }^{8}$ Because local traders are endowed with an informational (dis-)advantage regarding the local (all non-local) assets, they specialize and only trade in the local asset. ${ }^{9}$

Mathematically, speculator $j$ trading firm $i$ chooses asset holdings $\omega_{i j}$ to maximize a quadratic objective function:

$$
\max _{\omega_{i j}} E\left[\omega_{i j}\left(\theta_{i}-p_{i}\right) \mid e_{i}, \rho_{i}, \vec{p}\right]-\frac{c}{2} \omega_{i j}^{2}
$$

where $\vec{p}=\left[p_{1}, \ldots, p_{N}\right]^{\prime}$ denotes the $N \times 1$ vector of stock prices and the constant $c$, which is set to 1 without loss of generality, determines the trading cost.

Intuitively, each speculator maximizes the expected trading profit in the asset minus a quadratic trading cost that can be interpreted as an implicit or explicit transaction cost. This specific objective function ensures that each trader's demand remains finite and has been used in the existing literature, like Banerjee et al. (2018) and Vives (2011).

\footnotetext{
${ }^{6}$ This assumption is relaxed in Section 5 .

${ }^{7}$ This assumption is not crucial. Giving each speculator a private, partially revealing signal does not change any of the results.

${ }^{8}$ One could alternatively assume sequential trading over $N$ periods starting with the most downstream firm $i=1$ such that information can flow upstream over time.

${ }^{9}$ This assumption is made in several learning models with multiple risky assets. See e.g. Kumar and Seppi (1994), Foucault and Fresard (2014), Cespa and Foucault (2014) or Bhattacharya and O'Hara (2017). It is straightforward to rationalize this decision with a fixed trading cost.
} 
The market clearing condition for firm $i$ then requires that aggregate demand equals the potentially noisy supply: $\int_{0}^{1} \omega_{i j} d j=\bar{\xi}-\xi_{i}$ with $\xi_{i} \stackrel{i i d}{\sim} \mathcal{N}\left(0, \sigma_{\xi}\right)$. It follows that the equilibrium prices for all firms are given by:

$$
p_{i}=-\bar{\xi}+\mathbb{E}\left[\theta_{i} \mid e_{i}, \rho_{i}, \vec{p}\right]+\xi_{i}
$$

Each firm's stock price is thus simply equal to the expected payoff under the local speculators' information set plus an iid noisy supply shock. In the next section, I set the volatility of $\xi_{i}$ equal to zero $\left(\sigma_{\xi}=0\right)$ to emphasize the role of network uncertainty. ${ }^{10}$

\section{Model Solution}

In this section, I first solve for equilibrium prices in a fully transparent benchmark economy without opacity. Then, I compare this benchmark to the main equilibrium in which traders are uncertain about non-local links.

\subsection{Benchmark Equilibrium: Fully Transparent Network}

First, I solve for the cross-learning equilibrium in a fully transparent network without uncertainty, i.e. $\sigma_{\rho}=0$ and $\rho_{i}=\bar{\rho}$ for all $i \in\{2, \ldots, N\}$ (and $\rho_{1}=0$ as before). I use this frictionless benchmark equilibrium to separate the effect of network uncertainty on the cross-learning equilibrium.

As a first step, I can use the assumption that local traders observe $e_{i}$ perfectly and that $\sigma_{\rho}=0$ (and $\sigma_{\xi}=0$ ) to simplify the equilibrium price for firm $i$ in (3):

$$
p_{i}=e_{i}+\bar{\rho} \mathbb{E}\left[e_{i-1} \mid \vec{p}\right] .
$$

${ }^{10} \mathrm{I}$ also set the mean $\bar{\xi}$ equal to zero. Given that there is no risk premium (due to risk-neutrality), this assumption is without any loss of generality. 
Inspecting the expression for $p_{i}$ in equation (4), it is clear that traders in market $i+1$ would like to use the price of their downstream neighbor $\left(p_{i}\right)$ to extract information about $e_{i}$. However, $p_{i}$ is also clouded by an additional source of uncertainty, the local conditional expectation about $e_{i-1}$ which needs to be filtered out.

Lemma 1 (Optimal Signal Without Opacity) In the benchmark economy with $\sigma_{\rho}=0$ and $\sigma_{\xi}=0$, traders can combine the vector of stock prices $\vec{p}$ to recover a perfect signal about the local fundamental of their downstream neighbor: $z_{i}(\vec{p})=e_{i}$.

Proof: See Appendix A.2.1.

Lemma 1 shows that local traders can combine the $N$ stock prices to an optimal signal $z_{i}(\vec{p})$ that reveals their relevant shock $e_{i-1}$. As indicated above, this signal cannot be inferred from the local price $p_{i-1}$ alone because this price also contains non-local information through the traders' conditional expectations about $e_{i-2}$. Consider for a moment that traders in location $i$ only learned from the price of their downstream neighbor $(i-1)$ and traders in this location follow the same strategy and learn from their downstream neighbor $(i-2)$. In this case, $p_{i-1}$ is exposed to $e_{i-2}$ through the traders' cross-learning. As a result, traders in market $i$ have to filter out this source of noise from $p_{i-1}$ to learn efficiently about $e_{i-1}$. As a consequence, the optimal price signal for any firm $i$ depends on the the prices of all of its downstream neighbors. Note, however, that there are two special firms in the network that do not face this problem. First, traders in the market of the most downstream firm $i=1$ as this firm is, by definition, not related to another firm. Second, traders in market $i=2$ who can learn from $p_{1}$ efficiently as they know their firm's exposure to firm $i=1$ and face no uncertainty about other connections of this firm $\left(\rho_{1}=0\right)$. 
Proposition 1 (Benchmark Equilibrium) In an economy without opacity $\left(\sigma_{\rho}=0\right)$ and without noisy supply $\left(\sigma_{\xi}=0\right)$, there exists a unique fully revealing equilibrium in which the stock price is given by $p_{i}=\theta_{i}$ for all $i \in\{1, \ldots, N\}$.

Proof: See Appendix A.2.2.

Proposition 1 shows that in the absence of network uncertainty, stock prices are fully revealing and perfectly reflect the firms' future payoff $\theta_{i}$. In particular, there is no shock propagation at all in the economy because local prices only depend on local payoffs $\left(\theta_{i}\right)$ and are therefore only correlated with prices of direct neighbors.

As a result, if there is no uncertainty about the connections between other firms, all prices can be perfectly interpreted and the economy reaches the first-best outcome. Thus, somewhat paradoxically, even though each trader understands and uses all prices (Lemma 1), only local fundamental shocks from the local firm's downstream market are reflected in the stock price (Proposition 1). Intuitively, precisely the fact that all prices are observed allows local traders to filter out unrelated noise in prices and to recover the private signal of traders in neighboring markets. Next, I analyze the economy with opaque connections $\left(\sigma_{\rho}>0\right)$ and show that equilibrium prices differ drastically from their benchmark values.

\subsection{Cross-Learning Equilibrium: Opaque Network}

Next, I solve for the equilibrium in the main model in which firms face uncertainty about the intensity of non-local firm connections, $\rho_{-i} \sim \mathcal{N}\left(\bar{\rho}, \sigma_{\rho}^{2}\right)$. As argued verbally before, this deviation from the benchmark setup prevents upstream firms $(i>2)$ from using the optimal price signal in Lemma 1. To see this friction, consider the simplified expression for firm $i$ 's stock price (again, with $\sigma_{\xi}=0$ ):

$$
p_{i}=e_{i}+\rho_{i} \mathbb{E}\left[e_{i-1} \mid \vec{p}\right] .
$$


As in the benchmark model, $p_{i}$ reflects information about the local productivity shock $e_{i}$ and the traders' conditional expectation of the local shock for the downstream neighbor, $e_{i-1} \cdot{ }^{11}$ However, in sharp contrast to the benchmark model, equation (5) cannot be easily inverted by traders in the upstream market to back out $e_{i}$. Intuitively, the term $\rho_{i} \mathbb{E}\left[e_{i-1} \mid \vec{p}\right]$ depends on firm $i$ 's connectivity to $i-1\left(\rho_{i}\right)$. Because $\rho_{i}$ is unknown to traders in market $i+1$, this term represents non-fundamental noise in $p_{i}$ and prevents traders in the upstream market from perfectly learning $e_{i}$. Consequently, network opacity in the form of uncertainty about non-local $\rho_{i}$ acts like the traditionally assumed noisy demand or supply shocks and renders the learning problem non-degenerate such that prices are non-revealing.

Proposition 2 (Opacity Equilibrium) In an economy with opacity $\left(\sigma_{\rho}>0\right)$ but without noisy supply $\left(\sigma_{\xi}=0\right)$, there exists a unique linear equilibrium with the following price function for firm $i \in\{1, \ldots, N\}$ :

$$
\begin{aligned}
& p_{1}=e_{1} \\
& p_{2}=e_{2}+\rho_{2} e_{1} \\
& p_{i}=e_{i}+\rho_{i} \gamma_{i} \sum_{j=1}^{i-1} \alpha_{i j} e_{i-j} \quad \forall i \geq 3
\end{aligned}
$$

where the coefficients $\gamma_{i}$ and $\alpha_{i j}$ are different from zero almost surely and explicitly defined in Appendix A.2.3.

Proof: See Appendix A.2.3.

Proposition 2 shows firm $i$ 's equilibrium stock price in the economy with opacity. As before in the benchmark equilibrium, all stock prices depend on the local fundamental $\left(e_{i}\right)$

${ }^{11}$ Note that the private signals $e_{i}$ and $\rho_{i}$ do not help local traders to forecast the non-local productivity component $e_{i-1}$ which is formally shown below. 
and the local firm's exposure to the downstream neighbor $\left(\rho_{i}\right)$, reflecting the local traders' perfect knowledge about these two local shocks. Moreover, the equilibrium prices for the most downstream firms, $i=1$ and $i=2$ are not affected by opacity and still reveal the overall payoff $\theta_{i}=e_{i}+\rho_{i} e_{i-1}$ perfectly. Traders in market $i=1$ are, by definition, not exposed to non-local shocks. Similarly, traders in market $i=2$ can perfectly learn $e_{1}$ from $p_{1}$ and are therefore not exposed to non-local shocks neither. More upstream firms, however, face a more complicated learning problem. Consider, for example, firm $i=2$ 's upstream neighbor firm $i=3$. Traders in this firm's market, would like to learn the shared shock $e_{2}$ from $p_{2}$ to have a more precise forecast of the firm's composite cash flow. Because these traders are perfectly rational, they know that $p_{2}$ is, in part, driven by variation in $p_{1}$ as traders in market $i=2$ learn from this price signal. Consequently, traders in market $i=3$ do the best they can to filter out this non-local variation. However, as these traders face uncertainty about $\rho_{2}$, they can only partially filter out $\rho_{2} e_{1}$ by relying on the optimal price signal $\widetilde{z}_{3}\left(p_{2}, p_{1}\right)=p_{2}-\bar{\rho} p_{1}=e_{2}+\widetilde{\rho}_{2} e_{1}$. Here, $\widetilde{\rho}_{i} \equiv \rho_{i}-\bar{\rho}$ denotes the traders' realized forecast error about firm $i$ 's exposure to firm $i-1$.

This learning friction has two immediate implications for $p_{3}$. First, the price is now also exposed to non-local fundamental shocks $\left(e_{1}\right)$. Second, the price is also affected by surprises in the traders' assessment of firm $i=2$ 's linkage to firm $i=1\left(\widetilde{\rho}_{2}\right)$. Interestingly, the informational content of the adjusted price signal $\widetilde{z}_{3}$ also depends on the realized value $e_{1}$. In particular, the price signal becomes less informative the higher the payoff in unrelated firm $i=1$. Intuitively, traders in market $i=3$ anticipate more non-local variation in $p_{2}$ in this case which incentivizes them to lower the Bayesian weight on this signal.

In general, precisely the fact that upstream firms, like $i=3$, cannot perfectly use all 
information in their downstream neighbor's price leads to the propagation of shocks in this setup. Thus, shocks from unrelated firms in the first layer have an impact on prices of firms in higher layers. This mechanism is therefore fundamentally different from alternative models of learning-based financial contagion such as Admati (1985) or Kodres and Pritsker (2002), in which all asset prices are observed without friction and agents' learning from unrelated prices leads to non-local shock exposure.

\section{Opacity, Propagation, and Noise}

In this section, I study the implications of network opacity on the propagation of nonlocal shocks and the impact of noise trading. To obtain closed-form solutions, I restrict most of the analysis to an economy with $N=3$. This setting captures the most crucial feature of the model because it implies that the three firms are pairwise connected but there is no direct link between firms $i=1$ and $i=3$.

\subsection{Shock Propagation}

Next, I provide explicit expressions for the three firms' shock exposures. I put particular emphasis on the propagation of non-local shocks originating in one of the two more downstream firms because these shocks are transmitted through the traders' cross-asset learning. The results in Proposition 1 show that this cross-learning exposes stock prices to non-local shocks. In particular, the fact that traders in asset $i=3$ are unable to perfectly filter out non-local noise from $p_{2}$ allows for an effect of $e_{1}$ on firm $i=3$ 's stock price.

Corollary 1 (Fundamental Shock Propagation) If the underlying network is opaque ( $\sigma_{\rho}>0$ ) and there is no noisy supply risk $\left(\sigma_{\xi}=0\right)$, the sensitivities of stock prices $p_{i}$ with respect to 
non-local fundamental shocks are given by:

$$
\begin{aligned}
& \frac{\partial p_{3}}{\partial e_{2}}=\rho_{3} \times \frac{\sigma_{e}^{2}}{\sigma_{e}^{2}+\sigma_{\rho}^{2} e_{1}^{2}} \\
& \frac{\partial p_{3}}{\partial e_{1}}=\rho_{3} \times \frac{\left(\rho_{2}-\bar{\rho}\right) \sigma_{e}^{4}+\sigma_{\rho}^{2} \sigma_{e}^{2}\left(\rho_{3} \sigma_{e}^{2}-\left(\rho_{2}-\bar{\rho}\right) e_{1}-2 e_{2}\right) e_{1}}{\left(\sigma_{e}^{2}+\sigma_{\rho}^{2} e_{1}^{2}\right)^{2}} \\
& \frac{\partial p_{2}}{\partial e_{1}}=\rho_{2}
\end{aligned}
$$

as before the cross-firm linkages are distributed as $\rho_{2}, \rho_{3} \stackrel{\text { iid }}{\sim} \mathcal{N}\left(\bar{\rho}, \sigma_{\rho}^{2}\right)$ and the local fundamental shocks are distributed as $e_{i} \stackrel{i i d}{\sim} \mathcal{N}\left(0, \sigma_{e}^{2}\right)$. All sensitivities of $p_{i}$ with respect to local fundamentals $\left(e_{i}\right)$ are equal to one and those with respect to upstream fundamentals $\left(e_{i+1}\right.$ and $\left.e_{i+2}\right)$ are equal to zero.

Proof: See Appendix A.2.4.

Corollary 1 shows the sensitivities of stock prices with respect to fundamental shocks. Given that local traders observe the local shock $\left(e_{i}\right)$ perfectly, the sensitivity with respect to $e_{i}$ equals unity for all three firms. Moreover, the sensitivity to all non-local upstream shocks is equal to zero because upstream prices do not contain any valuable information for downstream firms. However, firms $i=2$ and $i=3$ are directly exposed to the local shocks of firm $i-1$ through the payoff structure. Therefore, $p_{2}$ and $p_{3}$ should respond to changes in these two shocks and Corollary 1 shows that this intuition is indeed correct. In particular, firm $i=2$ 's sensitivity to $e_{1}$ is equal to $\rho_{2}$ and thus identical to that in the benchmark equilibrium without opacity. Interestingly, the exposure of firm $i=3$ 's price to $e_{2}$ is not equal to its benchmark value $\left(\rho_{3}\right)$ but also reflects the fact that this firm's traders face a considerable amount of uncertainty when learning about $e_{2}$. More specifically, the term $\frac{\sigma_{e}^{2}}{\sigma_{e}^{2}+\sigma_{\rho}^{2} e_{1}^{2}}$ captures the informational content of these traders' price signal $p_{2}-\bar{\rho} p_{1}$. Therefore, network opacity decreases the diffusion of information about $e_{2}$ to $p_{3}$ because 
it obfuscates the downstream price $p_{2}$.

Most interestingly, the price of firm $i=3$ also depends on the fundamental shock of the unrelated firm $i=1\left(e_{1}\right)$. This sensitivity, in turn, depends on the two dimensions of uncertainty, fundamental $\left(\sigma_{e}\right)$ and network uncertainty $\left(\sigma_{\rho}\right)$. Moreover, it also depends on the random fundamentals $\left(e_{1}\right.$ and $\left.e_{2}\right)$ and firm $i=2$ 's excess connectivity to firm $i=1\left(\rho_{2}-\right.$ $\bar{\rho})$. As a result, the sensitivities $\frac{\partial p_{3}}{\partial e_{2}}$ and $\frac{\partial p_{3}}{\partial e_{1}}$ are (non-normal) random variables. To better understand their statistical behavior, I compute the expected sensitivities conditional on the network linkages $\left(\vec{\rho}=\left[\rho_{2}, \rho_{3}\right]^{\prime}\right)$ next.

Corollary 2 (Expected Shock Propagation Given Linkages) If the underlying network is opaque $\left(\sigma_{\rho}>0\right)$ and there is no noisy supply risk $\left(\sigma_{\xi}=0\right)$, the expected price sensitivities are given by:

$$
\begin{aligned}
& \mathbb{E}\left[\frac{\partial p_{3}}{\partial e_{2}} \mid \vec{\rho}\right]=\rho_{3} \Gamma_{1}\left(\sigma_{\rho}\right) \in\left[0, \rho_{3}\right] \\
& \mathbb{E}\left[\frac{\partial p_{3}}{\partial e_{1}} \mid \vec{\rho}\right]=\rho_{3}\left(\rho_{2}-\bar{\rho}\right) \frac{1-\Gamma_{1}\left(\sigma_{\rho}\right)}{\sigma_{\rho}^{2}} \in\left[0, \rho_{3}\left(\rho_{2}-\bar{\rho}\right)\right] \\
& \mathbb{E}\left[\frac{\partial p_{2}}{\partial e_{1}} \mid \vec{\rho}\right]=\rho_{2} .
\end{aligned}
$$

All remaining price sensitivities are equal to zero or one and given in Corollary 1. The function $\Gamma_{1}\left(\sigma_{\rho}\right)$ is given by $\Gamma_{1} \equiv 2 e^{\frac{1}{2 \sigma_{\rho}^{2}}} \sqrt{\frac{\pi}{2}} \sigma_{\rho}^{-1} \Phi\left(-\sigma_{\rho}^{-1}\right)$ with $\Gamma_{1}(0)=1, \Gamma_{1} \geq 0$, and $\Gamma_{1}^{\prime} \leq 0$.

Proof: See Appendix A.2.5.

Corollary 2 provides analytical expressions for each firm's non-local price-shock sensitivities conditional on the underlying network structure. As expected, firm $i=2$ 's sensitivity to its downstream shock $e_{1}$ is simply equal to its exposure $\rho_{2}$ because there is no opacity for this firm. The two non-local sensitivities for the most upstream firm, however, depend on the level of opacity $\left(\sigma_{\rho}\right)$. In particular, the expected sensitivity of $p_{3}$ with respect to $e_{2}$ is given by $\rho_{3} \Gamma_{1}$ and therefore always smaller than $\rho_{3}$ in an opaque 

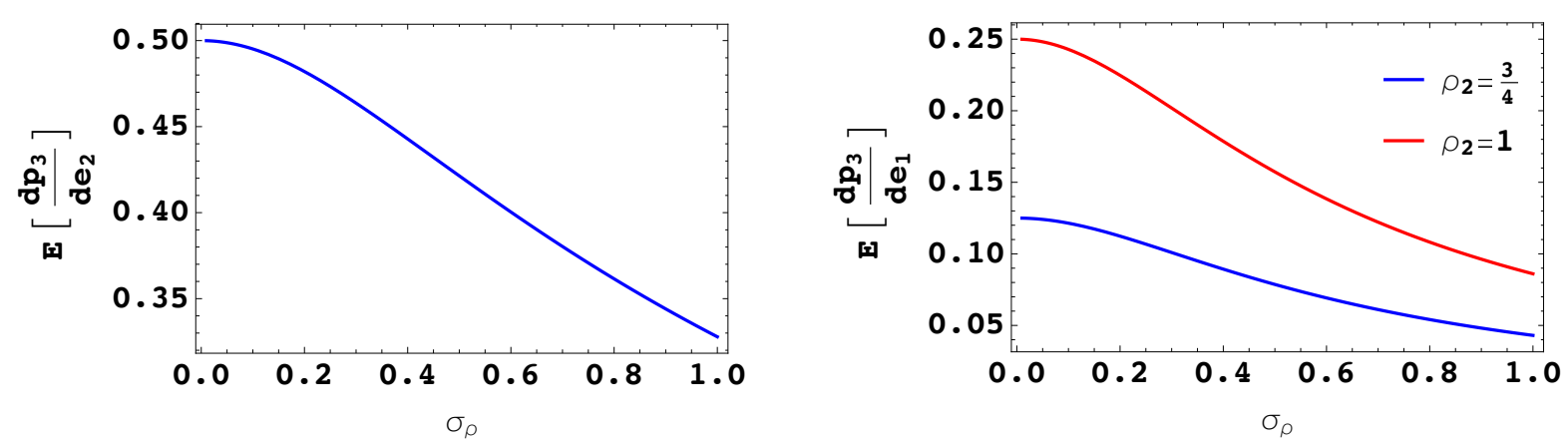

Figure 2: Plots of expected price-shock sensitivities for firm $i=3$. Parameters: $\bar{\rho}=\frac{1}{2}, \rho_{3}=\bar{\rho}$.

network. In a fully opaque network $\left(\sigma_{\rho} \rightarrow \infty\right)$, the sensitivity converges to 0 and $p_{3}$ is not affected by $e_{2}$ at all, even though the firm's payoff is exposed to this shock. In this limiting case, opacity fully crowds out information diffusion between prices $p_{2}$ and $p_{3}$. Most interestingly, $p_{3}$ is, on average, also exposed to the completely unrelated shock $e_{1}$. The expression in Corollary 2 shows that this sensitivity is proportional to $\rho_{2}-\bar{\rho}$, i.e. the surprise in the strength of firm $i=2$ 's connection to firm $i=1$. Intuitively, if the link between these two firms is unexpectedly strong, firm $i=3$ traders do not filter out enough non-local variation from the price signal based on $p_{2}$ and expose $p_{3}$ to a lot of non-local variation. Furthermore, the sensitivity decreases (in absolute value) in $\sigma_{\rho}$ as traders in $i=3$ rationally reduce their Bayesian weight on $p_{2}$ in the presence of more opacity.

Figure 2 evaluates these expected sensitivities numerically for different degrees of opacity and fixed values of $\bar{\rho}, \rho_{2}$, and $\rho_{3}$. It can be seen that more opacity generally crowds out the intensity of propagation as traders in market $i=3$ rationally anticipate a lower signal-noise ratio in $p_{2}$ and reduce their (Bayesian) exposure to the price signal. Concerning the sensitivity of $p_{3}$ with respect to $e_{1}$, the plot confirms that a stronger exposure between firms $i=1$ and $i=2$ increases the sensitivity of $p_{3}$ to the non-local shock $e_{1}$. Intuitively, a higher value of $\rho_{2}$ implies that traders in market $i=2$ have a 
stronger incentive to learn about $e_{1}$ from $p_{1}$. As a result, the equilibrium price $p_{2}$ is more strongly exposed to this non-local shock. As traders in market $i=3$ are not able to perfectly filter out this non-local noise from $p_{2}, e_{1}$ enters these traders' conditional expectation about $\theta_{3}$ (through $e_{2}$ ) and affects the equilibrium price $p_{3}$.

Next, I analyze the conditional covariances between the three asset prices. In the fullytransparent benchmark economy the covariance between adjacent assets is just equal to $\rho_{i} \sigma_{e}^{2}$ while assets $i=1$ and $i=3$ are unrelated. As I show below, these results are significantly changed in an opaque network.

Corollary 3 (Conditional Covariance Given Linkages) If the underlying network is opaque $\left(\sigma_{\rho}>0\right)$ and there is no noisy supply risk $\left(\sigma_{\xi}=0\right)$, the conditional covariances are given by:

$$
\begin{aligned}
& \operatorname{Cov}\left(p_{3}, p_{2} \mid \vec{\rho}\right)=\rho_{3} \sigma_{e}^{2}\left(\Gamma_{1}\left(\sigma_{\rho}\right)+\rho_{2}\left(\rho_{2}-\bar{\rho}\right) \Gamma_{2}\left(\sigma_{\rho}\right)\right) \\
& \operatorname{Cov}\left(p_{3}, p_{1} \mid \vec{\rho}\right)=\rho_{3}\left(\rho_{2}-\bar{\rho}\right) \frac{\sigma_{e}^{2}\left(1-\Gamma_{1}\left(\sigma_{\rho}\right)\right)}{\sigma_{\rho}^{2}} \\
& \operatorname{Cov}\left(p_{2}, p_{1} \mid \vec{\rho}\right)=\rho_{2} \sigma_{e}^{2}
\end{aligned}
$$

with the function $\Gamma_{2}\left(\sigma_{\rho}\right)$ defined as $\Gamma_{2} \equiv \frac{1}{2 \sigma_{\rho}^{2}} e^{\frac{1}{2 \sigma_{\rho}^{2}}} \int_{1}^{\infty} e^{\frac{t}{2 \sigma_{\rho}^{2}}} t^{-3 / 2} d t$ with $\Gamma_{2}(0)=1, \Gamma_{2} \geq 0$, and $\Gamma_{2}^{\prime} \leq 0$. The function $\Gamma_{1}\left(\sigma_{\rho}\right)$ is defined in Corollary 2 .

Proof: See Appendix A.2.6.

Corollary 3 provides analytic expressions for the conditional covariances between the three firms. It can be seen that the correlation between assets $i=1$ and $i=2$ is just equal to $\rho_{2}$ and therefore not affected by opacity at all. This result is intuitive because these two firms do not face any uncertainty regarding linkages of other (downstream) firms such that their covariance is equal to its benchmark value. However, the comovement between asset $i=3$ and the other two assets differs from its benchmark value and depends on the level of opacity. In particular, the covariance between $i=2$ and $i=3$ is not just equal 

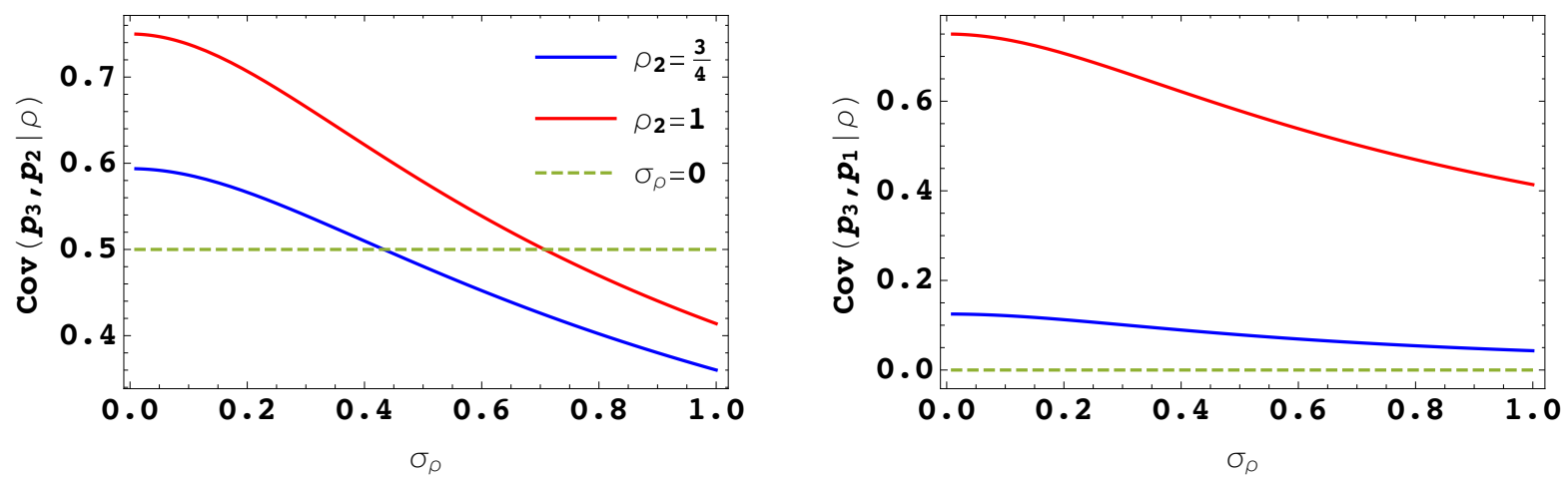

Figure 3: Plots of conditional covariances for firm $i=3$. Parameters: $\bar{\rho}=\frac{1}{2}, \rho_{3}=\bar{\rho}, \sigma_{e}=1$.

to $\rho_{3} \sigma_{e}^{2}$ but also depends on $\sigma_{\rho}$ and asset $i=2$ 's exposure to $i=1\left(\rho_{2}\right)$. Similarly, asset $i=3$ 's comovement with $i=1$ differs from its benchmark value of zero as long as there is opacity $\left(\sigma_{\rho}>0\right)$ and there is some surprise about $i=2^{\prime}$ 's linkage to $i=1\left(\rho_{2} \neq \bar{\rho}\right)$.

Figure 3 plots these conditional covariances and their benchmark values for asset $i=3$ against the level of opacity. It can be seen that the expected covariances are generally lower in more opaque networks and that a higher exposure between firms $i=1$ and $i=2$ increases the comovement. Interestingly, the covariance between the connected assets $i=2$ and $i=3$ can be lower or higher than its benchmark value $\rho_{3} \sigma_{e}^{2}$ (dashed line) depending on the degree of opacity. Intuitively, in the limit $\sigma_{\rho} \rightarrow \infty$ the network is fully opaque and traders in market $i=3$ do not use the price signal $p_{2}$ at all which prevents any correlation between both prices. If, however, there is only minor opacity there might be excess comovement between the two prices because they are not only related through their common exposure to $e_{2}$ but also trough that to $e_{1}$. Assets $i=3$ and $i=1$ are always excessively correlated as their benchmark correlation is equal to zero. Of course, if $\sigma_{\rho}=0$, $\rho_{i}=\bar{\rho}$ and both solid line merge with the dotted line. 


\subsection{Price Efficiency and Noise}

Next, I analyze how opacity affects price efficiency. To measure the informational content of prices, I follow the existing literature and rely on the conditional variance $\operatorname{Var}\left(e_{i} \mid \vec{p}\right)$ as an inverse measure of price efficiency. Hence, a low value for $\operatorname{Var}\left(e_{i} \mid \vec{p}\right)$ implies that the information in stock prices reduces a lot of prior variance $\left(\sigma_{e}^{2}\right)$ about fundamental shocks, $e_{i}$. Moreover, I focus on the two shocks traders would like to learn about $e_{1}$ and $e_{2} \cdot{ }^{12}$

Proposition 3 (Price Efficiency with Opacity) Prices are perfectly informative about the fundamental of the downstream firm $\left(e_{1}\right)$ but only partially informative about that of the intermediate firm $\left(e_{2}\right)$ :

$$
\operatorname{Var}\left(e_{i} \mid \vec{p}\right)= \begin{cases}0 & i=1 \\ \sigma_{e}^{2}-\frac{\sigma_{e}^{4}}{\sigma_{e}^{2}+p_{1}^{2} \sigma_{\rho}^{2}} & i=2\end{cases}
$$

Proof: See Appendix A.2.7.

Proposition 3 states that traders in market $i=2$ can learn $e_{1}$ perfectly from $p_{1}$ as shown before. As a result, the price system is perfectly informative with regards to this shock. Traders in market $i=3$, however, cannot perfectly infer the value of $e_{2}$ from their downstream neighbor's price $p_{2}$ as this price is clouded by the local traders' cross-learning (with uncertain intensity $\rho_{2}$ ) from $p_{1}$. As a consequence, the conditional variance about $e_{2}$ reflects these two sources of uncertainty. First, the variance increases in the degree of opacity $\sigma_{\rho}$. Second, it increases in $p_{1}$ because a higher price for asset $i=1$ increases the non-local variation in $p_{2}$ and makes it harder for $i=3$ traders to filter out information about $e_{2}$.

${ }^{12}$ Note that $e_{3}$ only affects the payoff of asset $i=3$ and that the local traders in this market are perfectly informed about $e_{3}$. 
Next, I allow for a positive supply shock variance $\sigma \xi$ which adds an additional source of risk to the three equilibrium prices.

Proposition 4 (Equilibrium with Noisy Supply) In an economy with opacity $\left(\sigma_{\rho}>0\right)$ and noisy supply $\left(\sigma_{\xi}>0\right)$, there exists a unique linear equilibrium with the following prices for firms $i=1,2,3$ :

$$
\begin{aligned}
& p_{1}=e_{1}+\xi_{1} \\
& p_{2}=e_{2}+\rho_{2} \gamma_{2} e_{1}+\xi_{2}+\rho_{2} \gamma_{2} \xi_{1} \\
& p_{3}=e_{3}+\rho_{3} \gamma_{3} e_{2}+\rho_{3} \gamma_{3}\left(\rho_{2}-\bar{\rho}\right) \gamma_{2} e_{1}+\xi_{3}+\rho_{3} \gamma_{3} \xi_{2}+\rho_{3} \gamma_{3}\left(\rho_{2}-\bar{\rho}\right) \gamma_{2} \xi_{1}
\end{aligned}
$$

where the coefficients $\gamma_{2}, \gamma_{3}>0$ are defined in the Appendix.

Proof: See Appendix A.2.8.

Proposition 4 shows the equilibrium prices in the economy with noisy supply. As before, non-local fundamental shocks propagate through the network such that $p_{3}$ is also exposed to the unrelated shock $e_{1}$. Moreover, in the presence of noisy supply these nonfundamental shocks also propagate. Therefore, the supply shock $\xi_{1}$ ends up affecting the stock price of the unrelated firm $i=3$.

Corollary 4 (Effect of Noise on Price Efficiency) If the underlying network is opaque ( $\sigma_{\rho}>$ $0)$ and there is noisy supply risk $\left(\sigma_{\xi}>0\right)$, an increase in noisy supply volatility leads to:

- a negative effect on price efficiency about $e_{1}: \frac{\partial \operatorname{Var}\left(e_{1} \mid \vec{p}\right)}{\partial \sigma_{\xi}}>0$

- an ambiguous effect on price efficiency about $e_{2}: \frac{\partial \operatorname{Var}\left(e_{2} \mid \vec{p}\right)}{\partial \sigma_{\xi}} \lessgtr 0$

Proof: See Appendix A.2.9.

Corollary 4 analyzes the impact of noisier supply risk on the informational content of prices. As in any conventional model with informed trading and exogenous noise, a 


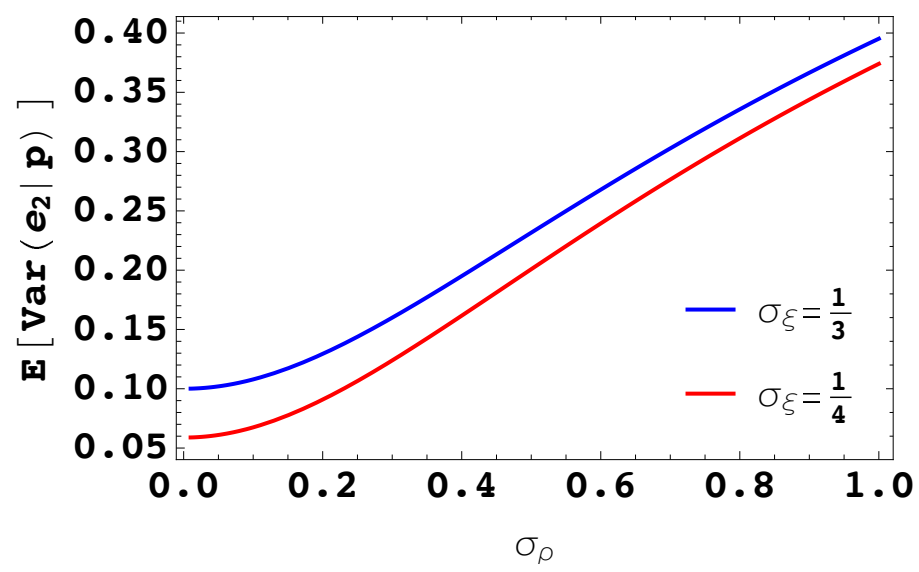

Figure 4: Expected conditional variance of $e_{2}$. Parameters: $\sigma_{e}=1$.

higher value of $\sigma_{\xi}$ increases the conditional variance about the fundamental shock for asset $i=1$. The intuition is straightforward: more volatile $\xi_{1}$ increases the non-fundamental variation in $p_{1}$ and renders this price signal less informative about $e_{1}$. More surprisingly, the Corollary also states that an increase in noisy supply can render stock prices more informative about $e_{2}$. I show in the appendix, that this counterintuitive result happens if the stock price of asset $i=1$ is sufficiently high. As shown before, traders in market $i=2$ rely a lot on $p_{1}$ in this case which, in turn, renders $p_{2}$ a very noisy signal for traders in market $i=3$. In this case, traders can benefit from more noise in $\xi_{i}$ because it reduces the incentive for traders in market $i=2$ to cross-learn from $p_{1}$.

Figure 4 plots the expected conditional variance of $e_{2}$ for different values of opacity and noisy supply risk. As expected, an increase in opacity $\left(\sigma_{\rho}\right)$ decreases price efficiency. Moreover, an increase in noisy supply risk from $\sigma_{\xi}=\frac{1}{4}$ to $\sigma_{\xi}=\frac{1}{3}$ has a similar effect and reduces price efficiency as well. 


\section{Extensions and Empirical Predictions}

\subsection{Market feedback}

In this section, I analyze the real effects of opacity. To this end, I introduce a real investment decision for the three firms and assume that the firm value for firm $i$ is given by:

$$
V_{i}=\theta_{i}+\theta_{i} K_{i}-\frac{1}{2} K_{i}^{2}
$$

As a result, each firm's terminal value depends on three components, (i) returns on assets in place, (ii) returns on a growth opportunity, and (iii) a quadratic investment cost. I follow the existing literature like Subrahmanyam and Titman (1999), Foucault and Gehrig (2008), Edmans et al. (2017) or Dessaint et al. (2018) and assume that the traded assets are solely claims to the firms' assets in place. ${ }^{13}$ This assumption keeps the model very tractable and does not change the financial market equilibrium derived earlier.

It follows from the linear-quadratic structure of $V_{i}$, that each firm optimally invests $K_{i}=\mathbb{E}_{i}\left[\theta_{i}\right]$ in the growth opportunity. I abstract from any information asymmetries between local traders and firms by assuming that each firm (or its manager) observes the local shocks $\left(e_{i}\right.$ and $\left.\rho_{i}\right)$ and all stock prices. As a consequence, optimal investment is given by:

$$
K_{i}=e_{i}+\rho_{i} \mathbb{E}\left[e_{i-1} \mid \vec{p}\right]
$$

Consequently, firm $i$ 's real investment decision increases if its manager becomes more optimistic about the composite productivity shock. This optimism can be derived from two sources, (i) the manager's private signal about the local shock $\left(e_{i}\right)$, and (ii) the manager's feedback signal from the vector of stock prices $(\vec{p})$.

\footnotetext{
${ }^{13} \mathrm{~A}$ previous version of the paper included the more general case in which the asset's payoff also included returns on the growth opportunity. Results for this alternative version are available on request.
} 
Proposition 5 (Expected Firm Values) The firms' expected firm values are given by:

$$
\begin{aligned}
& \mathbb{E}_{0}\left[V_{1}\right]=\frac{\sigma_{e}^{2}}{2} \\
& \mathbb{E}_{0}\left[V_{2}\right]=\frac{\sigma_{e}^{2}}{2}\left(1+\sigma_{\rho}^{2}+\bar{\rho}^{2}\right) \\
& \mathbb{E}_{0}\left[V_{3}\right]=\frac{\sigma_{e}^{2}}{2}\left(1+\sigma_{\rho}^{2}+\bar{\rho}^{2}-\frac{1}{2}\left(\sigma_{\rho}^{2}+\bar{\rho}^{2}\right) \Gamma_{3}\left(\sigma_{\rho}\right)\right)
\end{aligned}
$$

where the function $\Gamma_{3}\left(\sigma_{\rho}\right)$ is given by $\Gamma_{3} \equiv 2\left(1-e^{\frac{1}{2 \sigma_{\rho}^{2}}} \sqrt{2 \pi} \sigma_{\rho}^{-1} \Phi\left(-\sigma_{\rho}^{-1}\right)\right)$ with $\Gamma_{3}(0)=0, \Gamma_{3} \geq 0$ and $\Gamma_{3}^{\prime} \geq 0$.

Proof: See Appendix A.2.10.

Proposition 5 provides analytic expressions for the expected values of the three firms. It can be seen that the expected value for the most downstream firm only depends on $\sigma_{e}$ because this firm's fundamental is only affected by $e_{1}$. For the other two firms, however, the degree of network opacity $\left(\sigma_{\rho}\right)$ plays an important role as well. Interestingly, network opacity causes firm $i=3$ to be under-valued relative to firm $i=2$. In a fully transparent network $\left(\sigma_{\rho}=0\right)$, the two firm values are identical. As the network becomes more opaque, the difference between $E_{0}\left[V_{2}\right]$ and $E_{0}\left[V_{3}\right]$ increases. Both results are formalized in Corollary 5.

Corollary 5 (Disadvantage of Upstream Firm) Firm $i=3$ is less efficient than firm $i=2$ and the difference increases in $\sigma_{\rho}$ :

$$
\mathbb{E}_{0}\left[V_{2}-V_{3}\right] \geq 0 \text { and } \frac{\partial \mathbb{E}_{0}\left[V_{2}-V_{3}\right]}{\partial \sigma_{\rho}} \geq 0 .
$$

Proof: See Appendix A.2.11. 


\subsection{Integrated Trading}

Next, I relax one simplifying assumption of the main model and allow for integrated financial markets. To this end, I assume there to be only two groups of traders: (i) firm 3 specialists observing $e_{3}$ and $\rho_{3}$ as before, and (ii) universal specialists observing all $e_{i}$ and $\rho_{i}$. Traders from both groups trade in all three assets and firm 3 specialists have an incentive to cross-learn as they face incomplete information about $e_{1}, e_{2}$ and $\rho_{2}$. To prevent prices from perfectly revealing the private information of universal specialists, I also keep the assumption of noisy supply for assets $i=2$ and $i=3 .{ }^{14}$

Proposition 6 (Propagation with Integrated Trading) In an economy with opacity $\left(\sigma_{\rho}>0\right)$, noisy supply in assets $i=2,3\left(\sigma_{\xi}>0\right)$ and integrated trading with $e_{3}$-specialists and universal specialists, there exists a unique linear equilibrium with shock propagation:

$$
\frac{\partial p_{3}}{\partial e_{2}}, \frac{\partial p_{2}}{\partial e_{1}}, \frac{\partial p_{3}}{\partial e_{1}} \neq 0 \text { a. s. }
$$

Proof: See Appendix A.2.12.

Proposition 6 shows that the major result from before does not rely on the assumption of segmented markets. Network opacity leads to the propagation of non-local shocks even with integrated trading.

\subsection{Empirical Predictions}

The framework presented above yields several empirical implications regarding stock prices and real decisions in complex networks. First, it implies that opacity slows down the transmission of relevant non-local information between connected firms because it adds an additional layer of uncertainty to the peer's stock price. The model therefore 
provides a micro-foundation for the empirical findings in Cohen and Frazzini (2008) and Menzly and Ozbas (2010) that peer stock prices are informative but the transmission is only gradual and not instantaneous. Importantly, my framework offers sharp theoretical predictions regarding the intensity of information diffusion. ${ }^{15}$ As shown in Corollary 2 and Figure 2, information diffusion is higher in less opaque networks.

Second, the model implies that completely unrelated fundamental and financial shocks can affect prices and real investment decisions in opaque networks. This propagation of non-local shocks, in turn, leads to excess comovement between fundamentally unrelated firms which is a well-documented empirical finding (see e.g. Pindyck and Rotemberg (1993) or Barberis et al. (2005)). Again, the model provides theoretical guidance for the strength of this comovement. As shown in Corollary 3 and Figure 3, the excess comovement between firms $i=1$ and $i=3$ is higher if there is (i) more fundamental uncertainty, (ii) less opacity, and (iii) a surprisingly high or low linkage between $i=1$ and $i=2$.

Third, the model highlights a delicate interaction between opacity and other sources of non-fundamental noise in prices such as liquidity or noise trading. Corollary 4 shows that less risky noisy supply can lead to more efficient prices in opaque markets because it reduces traders' cross-learning incentives and the resulting negative effects on price efficiency. The model therefore implies that there should be cross-sectional differences regarding the response of price efficiency measures with respect to exogenous shocks to non-fundamental noise in prices. Moreover, the model provides an explanation for the empirical finding that price efficiency for the average firm has not increased over time despite overwhelming technological progress (Farboodi and Veldkamp (2017) and

${ }^{15}$ In recent empirical work, Cen et al. (2017) analyze information transmission along supply chains and find that limited attention slows down information diffusion as well. 
Farboodi et al. (2017)). As shown in Figure 4, a simultaneous upward shift in $\sigma_{\rho}$ (more opacity) can offset a downward shift in $\sigma_{\xi}$ (less noise trading) and can even lead to less efficient expected price efficiency.

Lastly, recent empirical work such as Foucault and Fresard (2014), Dessaint et al. (2018) and Williams and Xiao (2017) has established informational spillovers from peer prices to firms' real investment decisions. My model provides an alternative view on firms' crosslearning because it shows that fundamentally non-local shocks can affect firm investment even though the respective firm does not directly learn from this stock price. In an opaque network these unrelated shocks in peer prices cannot be fully controlled for which leads to shock propagation that is also reflected in firms' real decisions. As a direct consequence, Corollary 5 shows that firms in higher layers of the network face more network uncertainty and are, therefore, less valuable (particularly in highly opaque networks). Thus, the model implies that these firms should rely less heavily on peer stock prices which should be reflected in lower investment-price sensitivities. Moreover, this framework provides an alternative explanation for the recent finding in Gofman et al. (2018) that firms in higher supply chain layers earn a risk premium. In an opaque network, these firms are heavily exposed to opacity risk and face a very difficult cross-learning problem.

\section{Conclusion}

This paper provides a theoretical framework in which traders and firm managers learn from stock prices in opaque networks. This additional layer of uncertainty makes it impossible to filter out non-local noise from stock prices which leads to the propagation of these shocks through the network and excess comovement in prices. Traders and firm managers in higher layers of the network suffer the most from this source of risk and face 
less informative prices and less efficient trading/investment decisions.

It would be interesting for future empirical work to bring the model predictions to the data and establish a causal relationship between network opacity and trading/investment decisions. The model's tractability also offers several opportunities for future theoretical work. For instance, it could be interesting to study strategic disclosure by firm managers in such an opaque network. In particular, my model predicts that firm managers could manipulate the informational content of stock prices with public information regarding the exact relationship between their firm and the downstream neighbor $\left(\rho_{i}\right)$. Such a disclosure framework could provide a micro-foundation for the empirical finding in Ellis et al. (2012) that many firms try to conceal the identity of major customers in a customersupplier network. 


\section{References}

Admati, A. (1985). A noisy rational expectations equilibrium for multi-asset securities markets. Econometrica 53(3), 629-657.

Armstrong, C. S., S. Banerjee, and C. Corona (2013). Factor-loading uncertainty and expected returns. Review of Financial Studies 26(1), 158-207.

Banerjee, S., J. Davis, and N. Gondhi (2018). When transparency improves, must prices reflect fundamentals better? Review of Financial Studies 31(6), 2377-2414.

Banerjee, S. and B. S. Green (2015). Signal or noise? uncertainty and learning about whether other traders are informed. Journal of Financial Economics 117(2), 398-423.

Barberis, N., A. Shleifer, and J. Wurgler (2005). Comovement. Journal of Financial Economics 75(2), 283-317.

Bhattacharya, A. and M. O'Hara (2017). Can etfs increase market fragility? effect of information linkages in etf markets. Working Paper.

Bond, P., A. Edmans, and I. Goldstein (2012). The real effects of financial markets. Annual Review of Financial Economics 4, 339-360.

Cen, L., M. G. Hertzel, and C. Schiller (2017). Speed matters: Limited attention and supply-chain information diffusion. Working Paper.

Cespa, G. and T. Foucault (2014). Illiquidity contagion and liquidity crashes. Review of Financial Studies 27(6), 1615-1660.

Cohen, L. and A. Frazzini (2008). Economic links and predictable returns. Journal of Finance 63(4), 1977-2011. 
Dessaint, O., T. Foucault, L. Fresard, and A. Matray (2018). Noisy stock prices and corporate investment. Review of Financial Studies (forthcoming).

Easley, D., M. O'Hara, and L. Yang (2014). Opaque trading, disclosure, and asset prices: Implications for hedge fund regulation. Review of Financial Studies 27(4), 1190-1237.

Edmans, A., S. Jayaraman, and J. Schneemeier (2017). The source of information in prices and investment-price sensitivity. Journal of Financial Economics 126(1), 74-96.

Ellis, J. A., C. E. Fee, and S. E. Thomas (2012). Proprietary costs and the disclosure of information about customers. Journal of Accounting Research 50(3), 685-728.

Farboodi, M., A. Matray, and L. Veldkamp (2017). Where has all the big data gone? Working Paper.

Farboodi, M. and L. Veldkamp (2017). Long run growth of financial technology. Working Paper.

Foucault, T. and L. Fresard (2014). Learning from peers' stock prices and corporate investment. Journal of Financial Economics 111(3), 554-577.

Foucault, T. and T. Gehrig (2008). Stock price informativeness, cross-listings, and investment decisions. Journal of Financial Economics 88(1), 146-168.

Gofman, M., G. Segal, and Y. Wu (2018). Production networks and stock returns: The role of vertical creative destruction. Working Paper.

Goldstein, I., L. Yan, and L. Yang (2014). Speculation and hedging in segmented markets. Review of Financial Studies 27, 881-922.

Goldstein, I. and L. Yang (2015). Information diversity and complementarities in trading and information acquisition. Journal of Finance 70(4), 1723 - 1765. 
Grossman, S. and J. Stiglitz (1980). On the impossibility of informationally efficient markets. American Economic Review 70(3), 393-408.

Heinle, M., K. C. Smith, and R. E. Verrecchia (2018). Risk-factor disclosure and asset prices. The Accounting Review 93(2), 191-208.

Hope, O.-K., D. Hu, and H. Lu (2016). The benefits of specific risk-factor disclosures. Review of Accounting Studies 21(4), 1005-1045.

King, M. A. and S. Wadhwani (1990). Transmission of volatility between stock markets. Review of Financial Studies 3(1), 5-33.

Kodres, L. E. and M. Pritsker (2002). A rational expectations model of financial contagion. Journal of Finance 57(2), 769-799.

Kondor, P. (2012). The more we know about the fundamental, the less we agree on the price. Review of Economic Studies 79(3), 1175-1207.

Kumar, P. and D. J. Seppi (1994). Information and index arbitrage. Journal of Business 67(4), 481-509.

Mele, A. and F. Sangiorgi (2015). Uncertainty, information acquisition, and price swings in asset markets. Review of Economic Studies 82, 1533-1567.

Menzly, L. and O. Ozbas (2010). Market segmentation and crosspredictability of returns. Journal of Finance 65(4), 1555-1580.

Mondria, J. (2010). Portfolio choice, attention allocation, and price comovement. Journal of Economic Theory 145, 1837-1864.

Pasquariello, P. (2007). Imperfect competition, information heterogeneity, and financial contagion. Review of Financial Studies 20(2), 391-426. 
Pindyck, R. S. and J. J. Rotemberg (1993). The comovement of stock prices. Quarterly Journal of Economics 108(4), 1073-1104.

Subrahmanyam, A. and S. Titman (1999). The going-public decision and the development of financial markets. Journal of Finance 54(3), 1045-1082.

Veldkamp, L. (2006). Information markets and the comovement of asset prices. Review of Economic Studies 73(3), 823-845.

Vives, X. (2011). Strategic supply function competition with private information. Econometrica 79(6), 1919-1966.

Vives, X. and L. Yang (2016). A model of costly interpretation of asset prices. Working Paper.

Williams, R. and S. C. Xiao (2017). The real effects of stock prices on the supply chain. Working Paper. 


\section{A Appendix}

\section{A.1 Notation and Preliminary Derivations}

In this appendix, I sometimes work with the precision of a random variable instead of its variance. For a generic random variable $x$ with variance $\sigma_{x}^{2}$, I define its precision by $\tau_{x} \equiv \sigma_{x}^{-2}$.

I also frequently use two standard results from Bayesian updating. Consider a random variable $x$ that is Normally distributed with zero mean and precision $\tau_{x}$. Further consider an unbiased signal $s_{x}$ with precision $\tau_{s}$, then the first two conditional moments can be written as:

$$
\begin{aligned}
\mathbb{E}\left[x \mid s_{x}\right] & =\frac{\tau_{s}}{\tau_{x}+\tau_{s}} s_{x} \\
\operatorname{Var}\left(x \mid s_{x}\right) & =\left(\tau_{x}+\tau_{s}\right)^{-1} .
\end{aligned}
$$

\section{A.2 Proofs}

\section{A.2.1 Proof of Lemma 1}

It follows from equation (4) that the price for each firm is given by:

$$
\begin{aligned}
& p_{1}=e_{1} \\
& p_{i}=e_{i}+\bar{\rho} E\left[e_{i-1} \mid \vec{p}\right] \quad \forall i \geq 2 .
\end{aligned}
$$

Hence traders in market $i \geq 2$ can perfectly infer $e_{i-1}$ from $p_{i-1}$ as the unrelated term $\bar{\rho} E\left[e_{i-1} \mid \vec{p}\right]$ is a constant and can be filtered out perfectly. As a result, the price signal for firm $i \geq 3$ is given by:

$$
z_{i}(\vec{p})=p_{i-1}-\bar{\rho} \mathbb{E}\left[e_{i-2} \mid \vec{p}\right]=e_{i-1}
$$

Traders in market $i=2$ can simply use $z_{2}(\vec{p})=p_{1}$. 


\section{A.2.2 Proof of Proposition 1}

From Lemma 1 it follows that informed traders in all markets are able to observe the non-local component in $\theta_{i}\left(e_{i-1}\right)$ perfectly. As a result, $E\left[e_{i-1} \mid \vec{p}\right]$ in equation (4) becomes $e_{i-1}$ such that:

$$
p_{i}=e_{i}+\bar{\rho} e_{i-1} \quad \forall i \geq 2
$$

and $p_{1}=e_{1}$ as before.

\section{A.2.3 Proof of Proposition 2}

First, note that the prices of firms $i=1$ and $i=2$ are equal to their counterparts in Proposition 1 because these two firms are not affected by opacity. Thus,

$$
\begin{aligned}
& p_{1}=e_{1} \\
& p_{2}=e_{2}+\rho_{2} e_{1} .
\end{aligned}
$$

For firm $i=3$, opacity matters because it introduces noise into the price signal based on $p_{2}$. In particular, the optimal price signal for this firm is given by $\widetilde{z}_{3}=p_{2}-\bar{\rho} p_{1}=e_{2}+\widetilde{\rho}_{2} e_{1}$, where I define $\widetilde{\rho}_{i} \equiv \rho_{i}-\bar{\rho} \sim N\left(0, \sigma_{\rho}\right)$. The precision of this signal is given by $\tau_{z, 3}=\left(\sigma_{\rho}^{2} e_{1}^{2}\right)^{-1}$. As a result the stock price for firm $i=3$ is given by:

$$
p_{3}=e_{3}+\rho_{3} \mathbb{E}\left[e_{2} \mid \vec{p}\right]=e_{3}+\rho_{3} \gamma_{3}\left(e_{2}+\widetilde{\rho}_{2} e_{1}\right)
$$

with $\gamma_{3}=\frac{\sigma_{e}^{2}}{\sigma_{e}^{2}+e_{1}^{2} \sigma_{\rho}^{2}}$.

Repeating this step for other upstream firms, reveals that the price for firm $i \geq 3$ is given by:

$$
p_{i}=e_{i}+\rho_{i} \gamma_{i} \sum_{j=1}^{i-1} \alpha_{i j} e_{i-j}
$$


with $\gamma_{j}=\frac{\operatorname{Var}\left(\widetilde{z}_{i}(\vec{p}) \mid e_{i-1}\right)^{-1}}{\operatorname{Var}\left(\widetilde{z}_{i}(\vec{p}) \mid e_{i-1}\right)^{-1}+\sigma_{e}^{-2}}$ with $\widetilde{z}_{i}(\vec{p})$ representing the optimal price signal for traders in market $i$.

The coefficients $\alpha_{j}$ are given by:

$$
\alpha_{i j}=\Pi_{k=0}^{j-1} \widetilde{\rho}_{i-k} \gamma_{i-k}
$$

As a result, prices have to be computed in a bottom-up direction, i.e. starting with $i=1$.

\section{A.2.4 Proof of Corollary 1}

First, I set $N=3$ and compute the equilibrium prices based on the expression in Proposition 2.

$$
\begin{aligned}
& p_{1}=e_{1} \\
& p_{2}=e_{2}+\rho_{2} e_{1} \\
& p_{3}=e_{3}+\rho_{3} \frac{p_{1}^{-2} \sigma_{\rho}^{-2}}{\sigma_{e}^{-2}+p_{1}^{-2} \sigma_{\rho}^{-2}}\left(e_{2}+\left(\rho_{2}-\bar{\rho}\right) e_{1}\right)=e_{3}+\frac{\rho_{3} \sigma_{e}^{2}}{\sigma_{e}^{2}+e_{1}^{2} \sigma_{\rho}^{2}}\left(e_{2}+\widetilde{\rho}_{2} e_{1}\right) .
\end{aligned}
$$

The sensitivities simply follow from differentiating the three price equations with respect to the fundamental shocks $e_{1}, e_{2}$, and $e_{3}$.

\section{A.2.5 Proof of Corollary 2}

The expected covariances directly follow from the shock sensitivities in Corollary 1 together with the assumption that the $e_{i}$ shocks are iid normal with mean zero and variance $\sigma_{e}^{2}$. The function $\Gamma_{1}$ only depends on $\sigma_{\rho}$. It is straightforward to show that for $\sigma_{\rho}>0$, the function is positive and decreasing. Figure 5 evaluates the function for different values of $\sigma_{\rho}$. 

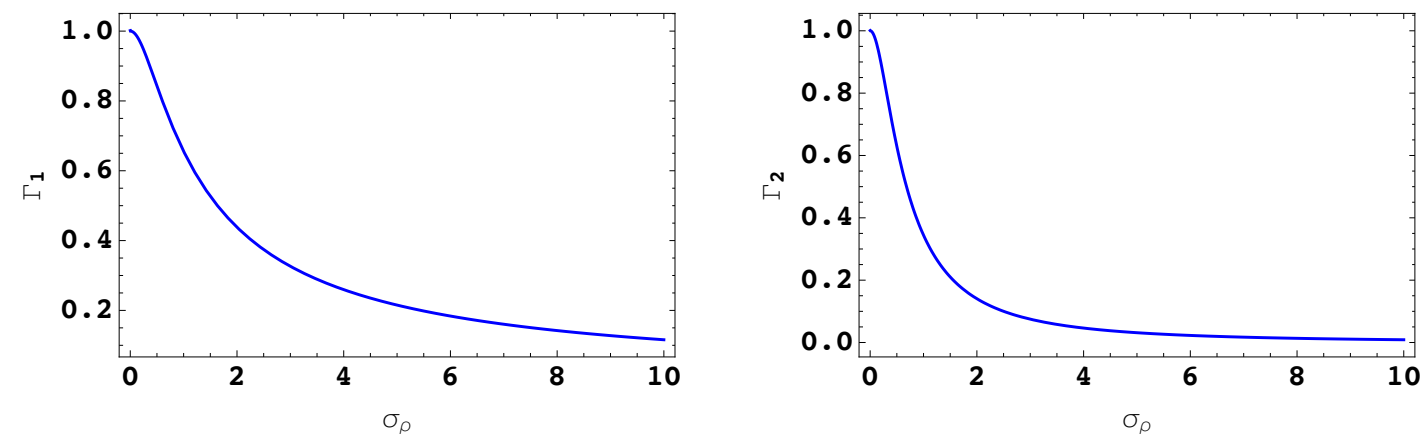

Figure 5: Plot of $\Gamma_{1}$, defined in Corollary 2, and $\Gamma_{2}$, defined in Corollary 3, as a function of $\sigma_{\rho}$.

\section{A.2.6 Proof of Corollary 3}

It follows from the equilibrium prices displayed in the proof of Corollary 1 that the conditional expectation of all three prices is equal to zero. Therefore, the conditional covariances can just be computed based on $\mathbb{E}\left[p_{i} p_{j} \mid \rho\right]$ using the fact that $e_{i} \stackrel{i i d}{\sim} \mathcal{N}\left(0, \sigma_{e}\right)$. The coefficient $\Gamma_{2}$ only depends on $\sigma_{\rho}$ and is displayed in Figure 5.

\section{A.2.7 Proof of Proposition 3}

First, the conditional variance of $e_{1}$ given prices is equal to zero because the price of asset $i=1$ reveals $e_{1}$ perfectly, $p_{1}=e_{1}$. Shock $e_{2} \sim \mathcal{N}\left(0, \sigma_{e}\right)$ can be partially learned from $p_{2}=e_{2}+\rho_{2} e_{1}$ and $p_{1}=e_{1}$. As shown before, the optimal signal is given by $z_{2}\left(p_{1}, p_{2}\right)=p_{2}-\bar{\rho} p_{1}$ with precision $\sigma_{\rho}^{-2} p_{1}^{-2}$. It follows from standard Bayesian updating that the conditional variance of $e_{2}$ is just equal to the inverse of prior precision plus signal precision:

$$
\operatorname{Var}\left(e_{2} \mid \vec{p}\right)=\frac{1}{\sigma_{e}^{-2}+\sigma_{\rho}^{-2} p_{1}^{-2}}
$$




\section{A.2.8 Proof of Proposition 4}

It follows from the market clearing condition that the price of asset $i$ is now given by:

$$
p_{i}=e_{i}+\rho_{i} \mathbb{E}\left[e_{i-1} \mid \vec{p}\right]+\xi_{i}
$$

For asset $i=1, \rho_{1}=0$ and so:

$$
p_{1}=e_{1}+\xi_{1}
$$

Traders in market $i=2$ can infer noisy information about $e_{1}$ from $p_{1}$ such that: $\mathbb{E}\left[e_{1} \mid p_{1}\right]=$ $\frac{\sigma_{\xi}^{-2}}{\sigma_{e}^{-2}+\sigma_{\xi}^{-2}} p_{1} \equiv \gamma_{2} p_{1}$. It follows that:

$$
p_{2}=e_{2}+\rho_{2} \gamma_{2}\left(e_{1}+\xi_{1}\right)+\xi_{2}
$$

Finally, traders in market $i=3$ base their expectation of $e_{2}$ on $p_{2}$ and $p_{1}$. In particular, they use the optimal signal $p_{2}-\bar{\rho} \gamma_{2} p_{1}$ which has precision $\frac{1}{\sigma_{\rho}^{2} p_{1}^{2} \gamma_{2}^{2}+\sigma_{\xi}^{2}}$. It follows that:

$$
p_{3}=e_{3}+\rho_{3} \gamma_{3}\left(p_{2}-\bar{\rho} \gamma_{2} p_{1}\right)=e_{3}+\rho_{3} \gamma_{3}\left(e_{2}+\xi_{2}+\widetilde{\rho}_{2} \gamma_{2}\left(e_{1}+\xi_{1}\right)\right)
$$

with $\gamma_{3}=\frac{\left(\sigma_{\rho}^{2} p_{1}^{2} \gamma_{2}^{2}+\sigma_{\xi}^{2}\right)^{-1}}{\sigma_{e}^{-2}+\left(\sigma_{\rho}^{2} p_{1}^{2} \gamma_{2}^{2}+\sigma_{\xi}^{2}\right)^{-1}}$.

\section{A.2.9 Proof of Corollary 4}

First, it follows from Proposition 4 that the conditional variances about $e_{1}$ and $e_{2}$ are given by:

$$
\operatorname{Var}\left(e_{1} \mid \vec{p}\right)=\left(\sigma_{e}^{-2}+\sigma_{\xi}^{-2}\right)^{-1}
$$

and

$$
\operatorname{Var}\left(e_{2} \mid \vec{p}\right)=\left(\sigma_{e}^{-2}+\frac{1}{\sigma_{\xi}^{2}+\gamma_{2}^{2} \sigma_{\rho}^{2} p_{1}^{2}}\right)^{-1}
$$


It then follows directly that $\operatorname{Var}\left(e_{1} \mid \vec{p}\right)$ always increases in $\sigma_{\xi}$. The impact on $\operatorname{Var}\left(e_{2} \mid \vec{p}\right)$ is more nuanced because $\gamma_{2}=\frac{\sigma_{\xi}^{-2}}{\sigma_{e}^{-2}+\sigma_{\xi}^{-2}}$ also depends on $\sigma_{\xi}$ :

$$
\frac{\partial \operatorname{Var}\left(e_{2} \mid \vec{p}\right)}{\partial \sigma_{\xi}}=\frac{2 \sigma_{e}^{4} \sigma_{\xi}\left(\sigma_{e}^{2}+\sigma_{\xi}^{2}\right)\left(\left(\sigma_{e}^{2}+\sigma_{\xi}^{2}\right)^{3}-2 p_{1}^{2} \sigma_{e}^{4} \sigma_{\rho}^{2}\right)}{\left(\left(\sigma_{e}^{2}+\sigma_{\xi}^{2}\right)^{3}+p_{1}^{2} \sigma_{e}^{4} \sigma_{\rho}^{2}\right)^{2}}
$$

As a result, the sign of this derivative is equal to that of $\left(\sigma_{e}^{2}+\sigma_{\xi}^{2}\right)^{3}-2 p_{1}^{2} \sigma_{e}^{4} \sigma_{\rho}^{2}$. In particular, more risky supply leads to a lower variance iff:

$$
\left(\sigma_{e}^{2}+\sigma_{\xi}^{2}\right)^{3}-2 p_{1}^{2} \sigma_{e}^{4} \sigma_{\rho}^{2}<0 \Leftrightarrow p_{1}^{2}>\frac{\left(\sigma_{e}^{2}+\sigma_{\xi}^{2}\right)^{3}}{2 \sigma_{e}^{4} \sigma_{\rho}^{2}}
$$

\section{A.2.10 Proof of Proposition 5}

First, note that the optimal investment for the three firms is given by:

$$
\begin{aligned}
& K_{1}=e_{1} \\
& K_{2}=e_{2}+\rho_{2} e_{1} \\
& K_{3}=e_{3}+\rho_{3} \frac{\sigma_{e}^{2}}{\sigma_{e}^{2}+e_{1}^{2} \sigma_{\rho}^{2}}\left(e_{2}+\widetilde{\rho}_{2} e_{1}\right)
\end{aligned}
$$

where again $\widetilde{\rho}_{2}=\rho_{2}-\bar{\rho}$.

Then the expected value of firm $i$ is given by $\mathbb{E}_{0}\left[V_{i}\right]=\frac{1}{2} \mathbb{E}_{0}\left[\mathbb{E}\left[\theta_{i} \mid e_{i}, \rho_{i}, \vec{p}\right]^{2}\right]$. Plugging in the conditional expectations computed before gives the expected firm values.

\section{A.2.11 Proof of Corollary 5}

It follows from the expressions for $\mathbb{E}_{0}\left[V_{3}\right]$ and $\mathbb{E}_{0}\left[V_{2}\right]$ in Proposition 5 that:

$$
\mathbb{E}_{0}\left[V_{2}-V_{3}\right]=\frac{\sigma_{e}^{2}}{4}\left(\sigma_{\rho}^{2}+\bar{\rho}^{2}\right) \Gamma_{3} \geq 0
$$




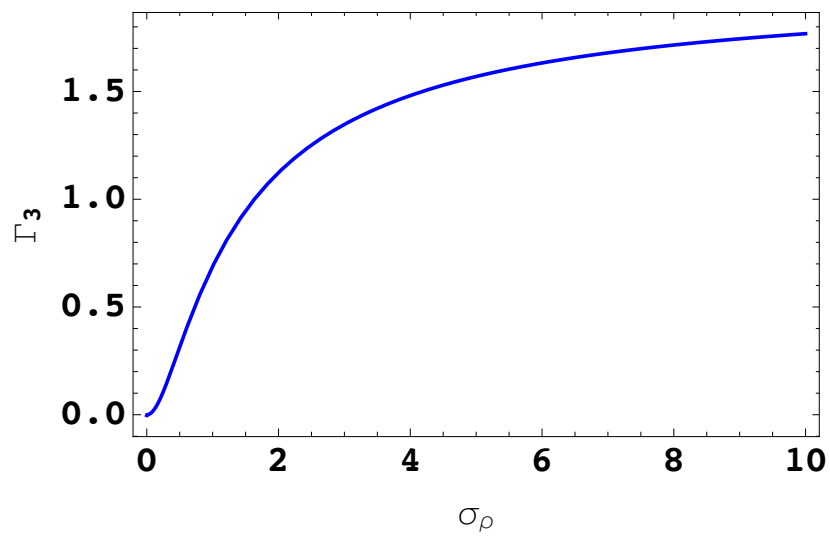

Figure 6: Plot of $\Gamma_{3}$, defined in Corollary 5 as a function of $\sigma_{\rho}$.

The coefficient $\Gamma_{3}$ is only a function of $\sigma_{\rho}$, weakly positive and increasing in $\sigma_{\rho}$. The function is evaluated in Figure 6.

\section{A.2.12 Proof of Proposition 6}

Note that $e_{3}$-specialists observe $\left(e_{3}, \rho_{3}\right)$ and universal specialists observe $\left(e_{1}, e_{2}, e_{3}, \rho_{2}, \rho_{3}\right)$. As before, the market clearing conditions for all assets are given by:

$$
\begin{aligned}
& p_{1}=e_{1}+\mathbb{E}\left[e_{1} \mid \rho_{3}, e_{3}, \vec{p}\right] \\
& p_{2}=e_{2}+\rho_{2} e_{1}+\mathbb{E}\left[e_{2}+\rho_{2} e_{1} \mid \rho_{3}, e_{3}, \vec{p}\right]+\xi_{2} \\
& p_{3}=e_{3}+\rho_{3} \mathbb{E}\left[e_{2} \mid \rho_{3}, e_{3}, \vec{p}\right]+e_{3}+\rho_{3} e_{2}+\xi_{3}
\end{aligned}
$$

Starting with asset $i=1$ : $e_{3}$-specialists can perfectly observe $e_{1}$ from $p_{1}$ such that $p_{1}=2 e_{1}$. As a result, the expression for $p_{2}$ becomes:

$$
p_{2}=e_{2}+\rho_{2} e_{1}+\mathbb{E}\left[e_{2} \mid \rho_{3}, e_{3}, \vec{p}\right]+e_{1} \mathbb{E}\left[\rho_{2} \mid \rho_{3}, e_{3}, \vec{p}\right]+\xi_{2}
$$

Next, $e_{3}-$ specialists can use the following two signals to learn about $e_{2}$ :

$$
\begin{aligned}
& z_{A}=p_{2}-\mathbb{E}\left[e_{2} \mid \rho_{3}, e_{3}, \vec{p}\right]-e_{1} \mathbb{E}\left[\rho_{2} \mid \rho_{3}, e_{3}, \vec{p}\right]-\bar{\rho} e_{1}=e_{2}+e_{1} \widetilde{\rho}_{2}+\xi_{2} \\
& z_{B}=\frac{p_{3}-2 e_{3}-\rho_{3} \mathbb{E}\left[e_{2} \mid \rho_{3}, e_{3}, \vec{p}\right]}{\rho_{3}}=e_{2}+\frac{1}{\rho_{3}} \xi_{3} .
\end{aligned}
$$


Therefore, the traders' conditional expectation of $e_{2}$ is given by:

$$
\mathbb{E}\left[e_{2} \mid e_{3}, \rho_{3}, \vec{p}\right]=\frac{\left(e_{1}^{2} \sigma_{\rho}^{2}+\sigma_{\xi}^{2}\right)^{-1}}{\sigma_{e}^{-2}+\left(e_{1}^{2} \sigma_{\rho}^{2}+\sigma_{\xi}^{2}\right)^{-1}+\rho_{3}^{2} \sigma_{\xi}^{-2}} z_{A}+\frac{\rho_{3}^{2} \sigma_{\xi}^{-2}}{\sigma_{e}^{-2}+\left(e_{1}^{2} \sigma_{\rho}^{2}+\sigma_{\xi}^{2}\right)^{-1}+\rho_{3}^{2} \sigma_{\xi}^{-2}} z_{B}
$$

Lastly, the traders' conditional expectation of $\rho_{2}$ is given by:

$$
\mathbb{E}\left[\rho_{2} \mid e_{3}, \rho_{3}, \vec{p}\right]=\bar{\rho}+\mathbb{E}\left[\widetilde{\rho}_{2} \mid e_{3}, \rho_{3}, \vec{p}\right]=\bar{\rho}+\gamma_{\rho}\left(\widetilde{\rho}_{2}+\frac{\widetilde{e_{2}}+\xi_{2}}{e_{1}}\right)
$$

with $\widetilde{\rho}_{2}=\rho_{2}-\bar{\rho}$ and $\widetilde{e_{2}}=e_{2}-\mathbb{E}\left[e_{2} \mid e_{3}, \rho_{3}, \vec{p}\right]$.

Hence, the three prices are given by:

$$
\begin{gathered}
p_{1}=2 e_{1} \\
p_{2}=e_{2}+\rho_{2} e_{1}+\xi_{2}+\gamma_{1}\left(e_{2}+e_{1} \widetilde{\rho}_{2}+\xi_{2}\right)+\gamma_{2}\left(e_{2}+\frac{1}{\rho_{3}} \xi_{3}\right)+\bar{\rho} e_{1}+e_{1} \gamma_{p}\left(\widetilde{\rho}_{2}+\frac{\widetilde{e}_{2}+\xi_{2}}{e_{1}}\right) \\
p_{3}=2 e_{3}+\rho_{3} e_{2}+\xi_{3}+\rho_{3}\left(\gamma_{1}\left(e_{2}+e_{1} \widetilde{\rho}_{2}+\xi_{2}\right)+\gamma_{2}\left(e_{2}+\frac{1}{\rho_{3}} \xi_{3}\right)\right) \\
\text { with } \gamma_{1} \equiv \frac{\left(e_{1}^{2} \sigma_{\rho}^{2}+\sigma_{\xi}^{2}\right)^{-1}}{\sigma_{e}^{-2}+\left(e_{1}^{2} \sigma_{\rho}^{2}+\sigma_{\xi}^{2}\right)^{-1}+\rho_{3}^{2} \sigma_{\xi}^{-2}} \geq 0, \gamma_{2} \equiv \frac{\rho_{3}^{2} \sigma_{\xi}^{-2}}{\sigma_{e}^{-2}+\left(e_{1}^{2} \sigma_{\rho}^{2}+\sigma_{\xi}^{2}\right)^{-1}+\rho_{3}^{2} \sigma_{\xi}^{-2}} \geq 0 \text {, and } \gamma_{p} \text { given by: } \\
\gamma_{p}=\frac{\frac{e_{1}^{2}}{\operatorname{Var}\left(\widetilde{e}_{2}\right)+\sigma_{\xi}^{2}}}{\sigma_{\rho}^{-2}+\frac{e_{1}^{2}}{\operatorname{Var}\left(\widetilde{e}_{2}\right)+\sigma_{\xi}^{2}}} \geq 0 .
\end{gathered}
$$

It follows that $p_{2}$ and $p_{3}$ are exposed to all downstream shocks almost surely. 